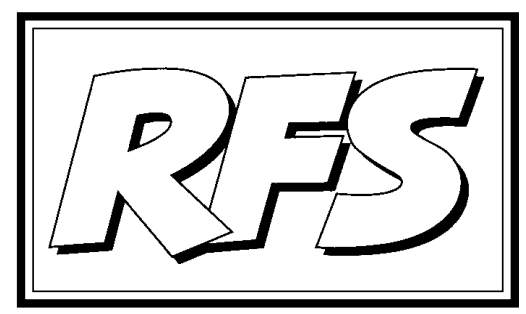

Revista de Fomento Social, 57 (2002), 85-100

\title{
El dilema del equilibrio vida personal versus vida profesional: un enfoque de recursos humanos ${ }^{1}$
}

J osé Antonio ARIZA MONTES

\section{Optimizar la inversión en personas}

La conciliación de la vida personal con la profesional es uno de los temas más interesantes en las relaciones laborales de principios de esta nueva década. En diferentes ámbitos del entorno empresarial, económico y social se apuesta de modo decidido por este asunto. Los mensajes enviados abogan por encontrar una ratio óptima entre tiempo dedicado a la vida profesional y tiempo invertido en la vida personal. El problema latente es que el entorno incita a que las prácticas habituales sean divergentes con los mensajes

1 J osé Antonio Ariza es también autor de un libro que versa sobre este asunto titulado "El reto del equilibrio: vida personal y profesional. Una guía práctica para decidir cómo emplear su tiempo". Editorial Desclée De Brouwer, Bilbao, 2002.

2 Profesor del área de Recursos Humanos del departamento de Economía General, Ciencias jurídicas y Sociología de la Facultad de CC.EE. y Empresariales-ETEA adscrita a la Universidad de Córdoba 
socialmente aceptables, de tal manera que la sociedad del siglo XXI, la supuesta sociedad del ocio, obliga a que la balanza se incline más hacia el lado profesional.

De forma preocupante, el mercado de trabajo cultiva, admira y encumbra a los empleados cuyo comportamiento se aproxima a la conducta tipo A, caracterizada por una lucha crónica e incesante por lograr más cosas en menos tiempo. Pese a ello, cada vez son más numerosas las evidencias que demuestran los efectos perniciosos que provoca el exceso de trabajo. La sobrecarga está directamente relacionada con la insatisfacción laboral, baja autoestima, niveles altos de colesterol, estrés e, incluso, mayor probabilidad de muerte por enfermedades coronarias.

En medio de este panorama tan gris, quizás alertados por el paisaje descrito, se encuentran medidas legislativas que apoyan directa o indirectamente la conciliación (Ley 39/1999 para promover la conciliación de la vida familiar y laboral de las personas trabajadoras, tendencia a reducir la jornada a 35 horas semanales o penalizaciones estipuladas en convenio por la realización de horas extraordinarias). Al mismo tiempo, surgen prácticas ingeniosas de empresas líderes en gestión de recursos humanos que son conscientes de la importancia que tiene el equilibrio en el buen funcionamiento organizativo ${ }^{3}$.

La gestión de personas únicamente adquirirá el protagonismo que merece cuando se introduzcan indicadores para su valoración. Desde el punto de vista de los parámetros utilizados para la evaluación de inversiones, la exhortación a realizar más cosas en menos tiempo pretende hacer más atractiva la inversión en personas, aumentando los ingresos y manteniendo constantes los gastos. La paradoja radica en que a largo plazo es probable que los costes vinculados al desequilibrio vida personal/profesional aumenten, de tal forma que no resulte tan interesante esa apelación al trabajo desmedido (Ariza, 2001). Las bajas laborales inducidas por el exceso de actividad, la financiación de tratamientos de desintoxicación por adicción al trabajo o el aumento de las demandas legales en relación con daños producidos por el estrés laboral, podrían replantear la rentabilidad de tan magnífica inversión.

3 Por ejemplo, el Programa "Diversidad" de Hewlett Packard pone a disposición de los empleados herramientas y políticas para alcanzar mayor armonía entre vida privada y laboral. 


\section{La sociedad del ocio... o la gran mentira}

El tiempo de cualquier persona empleada se divide en dos grandes áreas: trabajo y ocio ${ }^{4}$. En la sociedad del siglo XXI el tiempo de ocio adquiere una importancia crítica. Se le confiere un valor similar al trabajo, la familia o los amigos, y se sitúa como asunto prioritario por delante de la religión o la política. Así se desprende de una encuesta del CIS (1997) que, entre otros aspectos, destaca que un $66,0 \%$ de los españoles considera que "hay que trabajar lo mejor posible, pero sin que el trabajo interfiera en los demásaspectos de la vida".

Según un informe del Instituto Vasco de Estadística Eustat (1998), la manera de distribuir el tiempo está condicionada por factores vitales, gustos personales y por las oportunidades que ofrezca el entorno familiar y social ${ }^{5}$. Pero el modo de conjugar estos condicionantes viene determinado por el sexo y la situación laboral. De esta forma, la distribución del tiempo diario entre mujeres y hombres trabajadores muestra que las primeras dedican menos tiempo a tareas remuneradas y más a trabajos no retribuidos. En este sentido, mientras que las mujeres dedican por término medio 5 horas/día al trabajo remunerado y 2,5 horas/día a las tareas domésticas, los hombres emplean algo más de 6 horas/día y 1 hora/día en estas tareas respectivamente.

Entre otras conclusiones, el estudio pone de manifiesto que las mujeres trabajan cada día 59 minutos más que los hombres. En consecuencia, tienen menos tiempo para dedicarlo a las actividades de ocio y relajación. Así, mientras que un vasco dispone por término medio de más de cinco horas al día para el ocio, una conciudadana supera escasamente las cuatro.

Estas diferencias también se manifiestan respecto al modo de emplear el tiempo libre, sobre todo en los días festivos (ver figura 1). A grandes rasgos se advierte que las mujeres ocupadas disfrutan tan sólo de un 75,0\% del tiempo libre de los varones ocupados y ambos dedican casi la mitad de su

4 Como no podría ser de otro modo, este artículo pone su énfasis en las personas que desempeñan un trabajo remunerado y que tienen que decidir cómo equilibrar tiempo profesional y personal. Aún así, somos conscientes de que existen otros colectivos cuya problemática es completamente distinta: desempleados, trabajadores en precario, etc. Seguramente estas personas desearían sufrir los conflictos que se plantean en estas páginas.

5 Las circunstancias familiares condicionan enormemente el modo de empleo del tiempo: soltero, casado, con hijos pequeños, con personas mayores a cargo, etc. 
tiempo libre total a las actividades de ocio pasivo. La televisión es la gran protagonista como alternativa de uso del tiempo libre ${ }^{6}$.

FIGURA 1

Distribución del tiempo de ocio en días festivos

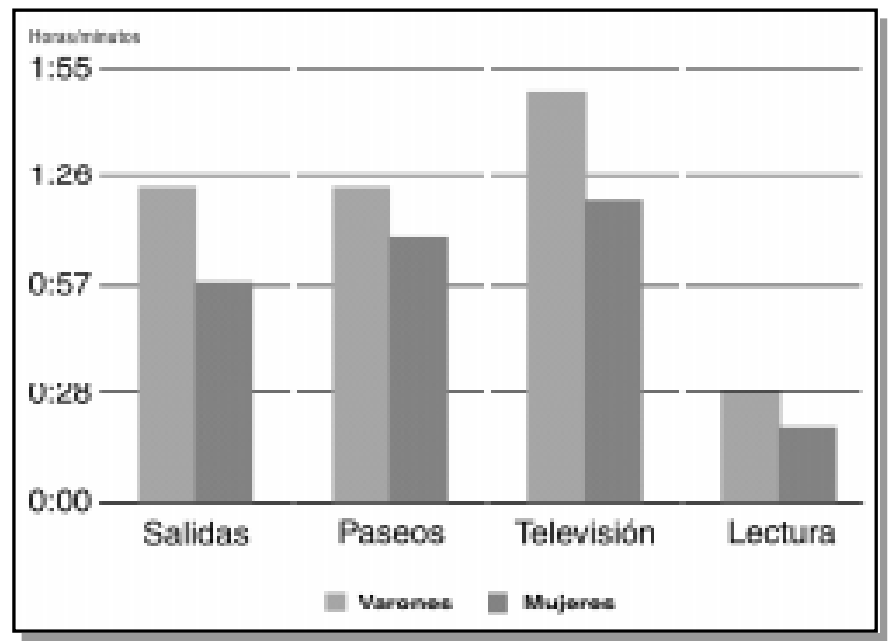

Fuente: Instituto Vasco de Estadística, Eustat (1998).

El tiempo de ocio está claramente condicionado por la actividad laboral. En este sentido, la reducción del tiempo dedicado al trabajo ha creado holguras importantes en el tiempo de ocio. Si a finales del siglo XIX las horas de trabajo semanales superaban las sesenta, a mediados del siglo pasado se generalizó en los países industrializados la jornada laboral de cuarenta horas semanales ${ }^{7}$. Según el Instituto Nacional de Estadística, en la actualidad, la

6 La distribución del tiempo libre de este estudio no incluye el tiempo dedicado a otro tipo de actividades no retribuidas que están adquiriendo un gran protagonismo durante los últimos años en la sociedad española, como son las tareas de voluntariado. Según un estudio de la Fundación BBVA, en España el número de voluntarios que dedican más de cuatro horas semanales a entidades no lucrativas asciende a 1.026 .478 personas.

7 En España el Estatuto de los Trabajadores institucionalizó en 1980 el número máximo de 40 horas de trabajo semanales a alcanzar en 1983. 
jornada media pactada por trabajador y año es de 1.702 horas, aunque el número de horas efectivamente trabajadas desciende hasta 1.648. Desde la década de los años cincuenta no se han producido descensos significativos en la reducción del tiempo dedicado al trabajo, aunque en la actualidad se habla con insistencia de la implantación de la jornada de treinta y cinco horas en diferentes ámbitos. Por otra parte, la experiencia del gobierno francés de reducir por ley la jornada de trabajo a treinta y cinco horas semanales está demostrando que sus efectos son altamente beneficiosos, aunque es cierto que no afectan por igual a toda la población ${ }^{8}$. En nuestro país, a corto plazo los efectos de la reducción son más dispersos e inciertos pero, según Hernández (1999), en el horizonte del largo plazo se constata la relación positiva generalizada entre reducción de jornada laboral, productividad y crecimiento económico.

La sociedad del ocio -o quizás del consumo de ocio- es un hecho incontestable a comienzos de este siglo, pero en este marco de referencia aparecen contradicciones difíciles de entender y que pueden sugerir que esta sociedad sea más teórica que real. Por un lado, la competitividad que domina nuestros días incita a una mayor dedicación al trabajo (Ios resultados del estudio de Eustat confirman que, de 1993 a 1998, el tiempo dedicado a la actividad profesional ha aumentado por término medio en 26 minutos/ día). Por otro, una reciente encuesta del CIS (2000) indica que, pese a que el $45,0 \%$ de los españoles pensaban que en términos generales el año 2000 les iba a ir mejor, sólo el 17,0\% creía que iban a disponer de más tiempo libre.

En definitiva, pese a que aparentemente el tiempo libre disponible en la

8 Una encuesta realizada por el Ministerio de Empleo y Solidaridad con más de 1.500 trabajadores con un año de experiencia bajo la Ley Aubry, en vigor desde enero de 2000, confirma el amplio apoyo social obtenido por ésta, aunque con matices. El 59,0\% de los asalariados declara haber experimentado una mejora global en su modo de vida. Según el estudio, los privilegios se notan más en los mandos de las empresas (69,0\%) que en los empleados no cualificados (49,0\%). Seis de cada diez encuestados afirman que la reducción del tiempo de trabajo ha significado una mejora global en su vida, un $28,0 \%$ declara no haber experimentado cambio alguno y un $13,0 \%$ cree que ha supuesto, incluso, una cierta degradación. Más que una reducción cotidiana y colectiva de la jornada laboral, la Ley Aubry es un sistema individualizado que se traduce en fiestas intersemanales o más días de vacaciones al año, a cambio de moderación salarial. La disponibilidad de mayor tiempo para la familia o para uno mismo y el respiro de los días libres parecen compensar un cierto deterioro y hasta un nuevo estrés en el trabajo, reconocido por un significativo 31,7\% de los encuestados (GonZÁLEZ CABEZAS, J .R., "El 59\% de los asalariados franceses en régimen de 35 horas dice vivir mejor". La Vanguardia, 15 de mayo de 2001). 
actualidad es más prolongado, lo cierto es que el aumento de los adictos al trabajo y de las personas que padecen estrés y desgaste profesional constituye un signo evidente de todo lo contrario.

\section{La adicción al trabajo como síntoma}

Bajo la perspectiva del cuadro descrito anteriormente no es de extrañar que existan cada vez más personas que sufren de adicción al trabajo, manifestando una compulsión obsesiva por trabajar de manera incesante. Para estos individuos la actividad profesional constituye el eje sobre el que gira la vida, la principal fuente de satisfacción y el significado mismo de ésta9 ${ }^{\text {. }}$ Los principales rasgos que caracterizan al adicto al trabajo se recogen en la figura 2.

Las personas que sufren esta adicción, propia de varones urbanos de clase media, están constantemente preocupadas por alcanzar un rendimiento máximo, tratan de dedicar cada vez más tiempo al trabajo -usurpándolo de la vida personal o familiar- y mantienen una sensación permanente de urgencia. Estos enfermos no son conscientes de que permanecer más tiempo en el lugar de trabajo no garantiza una mayor productividad. Esta incongruencia se manifiesta especialmente en los trabajos de elevado contenido intelectual. El enunciado de la Ley de los rendimientos decrecientes advierte que a partir de un número de horas de trabajo al día, el rendimiento extra que se produce es cada vez menor. Además, el tiempo adicional sobre el óptimo puede originar serios problemas a medio plazo.

El significado de esta ley es el siguiente. Las primeras horas de trabajo diarias producen rendimientos más que proporcionales. El esfuerzo se traduce en resultados inmediatos, visibles y directos, de tal manera que la dedicación al trabajo genera un sentimiento interior de satisfacción y reali-

9 Si hasta hace poco tiempo estar enganchado al trabajo era algo exclusivo de los puestos directivos, en la actualidad los profesionales liberales, eincluso personas que ocupan niveles operativos, están mostrando síntomas evidentes de padecer este trastorno. La última encuesta deUPSEuropean Monitor Business pone de manifiesto que los directivos españoles tienen graves dificultades para olvidarse del trabajo. Un 76,0\% declara mantener contacto con la empresa durante su tiempo de vacaciones por si surge algún imprevisto. Este porcentaje es muy elevado, sobre todo si lo comparamos con el $45,0 \%$ de franceses o el $57,0 \%$ de alemanes que manifiestan lo mismo. Además, un 10,0\% de los directivos españoles selleva trabajo para realizar en vacaciones, frente al 8,0\% de media europea (citado en Emprendedores, no 30, marzo de 2000). 
FIGURA 2

\section{Perfil del adicto al trabajo}

\begin{tabular}{|c|c|}
\hline $\begin{array}{l}\text { Perseno no adicto } \\
\text { al trabajo }\end{array}$ & $\begin{array}{l}\text { Persenta adicto } \\
\text { al trabajo }\end{array}$ \\
\hline Bisfruta con lo que hace (un thi) & $\begin{array}{l}\text { Lo que hace es para conseguir abo fun } \\
\text { medk) }\end{array}$ \\
\hline 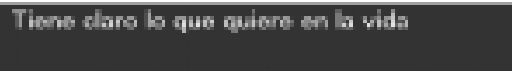 & 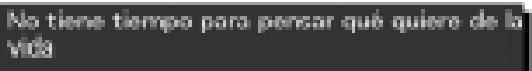 \\
\hline Trabsja para vhir & Vve para trabsjar \\
\hline Su vids persons espratiante & Su vida prolesicnal es gatrikante \\
\hline 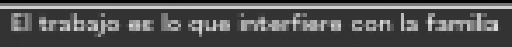 & 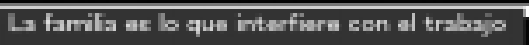 \\
\hline Watiene satiafaccian de su tiempo Itre & $\begin{array}{l}\text { Whatiene satiafaccian de su tiampo de } \\
\text { trabajp }\end{array}$ \\
\hline G tiempo ibre siempre le restita estasd & 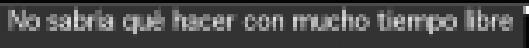 \\
\hline 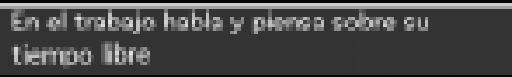 & 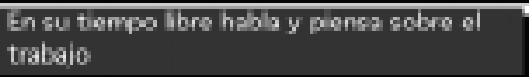 \\
\hline Active en ed trabajo y con el tiempo bare & $\begin{array}{l}\text { Activo en el trabajo y pasvo con su tiempo } \\
\text { libre }\end{array}$ \\
\hline 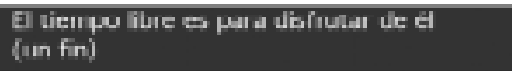 & 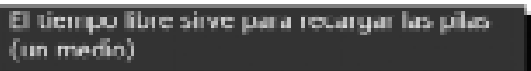 \\
\hline 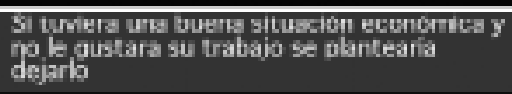 & 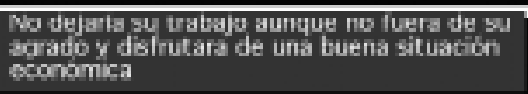 \\
\hline 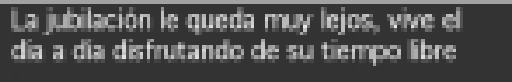 & 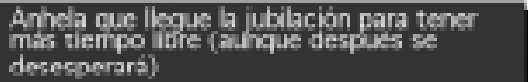 \\
\hline
\end{tabular}

Fuente: elaboración propia.

zación personal (área de realización). En esta área de realización, la motivación del empleado es muy elevada, poniendo en funcionamiento un efecto retroalimentador del rendimiento en calidad y cantidad. Una vez superadas un número de horas de trabajo al día -que varían de unas personas a otras y de unos días a otros- se entra en la zona de desgaste. Llegados a este punto, cada unidad de tiempo extra se traduce en resultados menos que proporcionales. En este contexto, el individuo siente que su esfuerzo no produce los

\section{ESTUDIOS}


resultados deseados, lo que se traduce en sentimientos de frustración, incompetencia, ineficacia, hostilidad, etc. En esta área, la utilidad marginal obtenida por cada hora de trabajo adicional no compensa el esfuerzo y la dedicación que se requiere. Si aún así el trabajador persiste en quedarse un rato más, se adentrará en el área de peligro, donde el desgaste psicológico continuado al que se encuentra sometido tarde o temprano afectará negativamente su salud. La zona de peligro se traspasa en jornadas de trabajo excesivas y se caracteriza por producir efectos negativos. Al dedicar un número de horas desproporcionado a la actividad laboral, la probabilidad de cometer errores aumenta de forma significativa, lo que se traduce en posibles rendimientos negativos. En conclusión, se podría hablar de una jornada de trabajo óptima (Área de realización), a partir de la cual seguir trabajando genera resultados cada vez menores (Área de desgaste), hasta el punto de producir rendimientos negativos si nos empeñamos en continuar (Área de peligro). No hay que olvidar que la actividad incesante es enemiga de la creatividad y de la innovación, lo que conduce a un descenso de la productividad a medio plazo.

Pese a todo, los adictos al trabajo justifican su adicción con argumentos de carácter económico ("debo esforzarme para ganar más dinero") o de proyección profesional ("tengo que trabajar más para promocionar a Jefe de..."). Pero la doctora Mabel Burin (2000) apunta que el elemento económico no es la motivación principal para tal dedicación al trabajo, sino sólo un modo de justificar la adicción. En el trasfondo del problema subyace un esfuerzo por huir de realidades subjetivas que provocan un vacío psíquico interior. El adicto se precipita en el universo laboral, obteniendo una sensación de aturdimiento que le sirve como remedio autorrecetado a su enfermedad. En cierto modo, estas sensaciones de alivio, euforia y despreocupación son similares a las que concurren en un drogadicto cuando consume su dosis.

Como se ha podido comprobar, en el origen de la adicción al trabajo se aprecia un germen de naturaleza interna pero, en muchas ocasiones, el contexto externo empuja con fuerza. Este problema es especialmente acuciante en los puestos directivos. En un entorno cada vez más hostil y competitivo no es de extrañar que las organizaciones aspiren a minimizar el número de directivos en relación con la plantilla total -en orden a reducir costes y burocracia- pero simultáneamente con mayores exigencias de calidad en la ejecución de sus responsabilidades. En definitiva, las organizaciones excelentes, en su afán de aplanar la estructura jerárquica, cada vez tienen menos directivos, pero los que quedan deben ser mejores. Y ser el 
mejor tiene también su coste. ¿Constituye la adicción al trabajo -originada en parte por un cúmulo de mayores exigencias- el tributo que la organización excelente tiene que pagar para mantener su elevado nivel de productividad y competitividad?

En definitiva, las demandas a las que debe responder con eficacia y eficiencia el directivo actual -y otros muchos profesionales- incitan a la dedicación compulsiva al trabajo en pos de los objetivos organizativos. Esta situación puede provocar la aparición de una de las enfermedades del siglo XXI: el estrés y el desgaste profesional.

\section{Algunas consecuencias del desequilibrio: El desgaste profesional y el karoshi}

Una cierta dosis de estrés es necesaria, e incluso aconsejable, para que el proceso de desarrollo y adaptación a las exigencias del medio proceda con normalidad. El organismo está preparado para asumir cierto grado de estimulación ambiental, y a niveles superiores o inferiores al idóneo, es necesario un esfuerzo para mantener el funcionamiento adecuado en los procesos fisiológicos. La aplicación de este principio permite formular una ley general del estrés: cuando la influencia del ambiente supera o no alcanza las cotas en las que el organismo responde con máxima eficiencia, éste percibe la situación como amenazante, peligrosa o desagradable, desencadenando una reacción de lucha o huida y/o una reacción de estrés, con hipersecreción de catecolamina y cortisol (González de Rivera, 1978). El rendimiento laboral de calidad, creativo, flexible y comprometido con los objetivos organizacionales, sólo se manifiesta en situaciones de estrés adecuado. Esta afirmación no es generalizable para todo tipo de trabajo, ya que cuanto más compleja y ambigua sea una tarea, más bajo será el nivel de estrés necesario para ser disruptivo (ver figura 3).

Si la estimulación ambiental es insuficiente y el trabajador se encuentra infrautilizado, éste acabará mostrando síntomas evidentes de monotonía y frustración. En el otro extremo, cuando la estimulación del ambiente supera los límites permisibles, la saturación continua y permanente del empleado terminarán quemándolo, padeciendo de esta manera el síndrome del quemado o burnout ${ }^{10}$. Este concepto ha surgido íntimamente relacionado con el

10 La etiqueta burnout se debe a Herbert Freudenberger (1974), psicólogo clínico, que la empleó para describir un conjunto de síntomas físicos y psíquicos sufridos por personal sanitario. 
estrés, por lo que resulta difícil establecer una diferencia entre ambos. La única diferencia, más aparente que real, es que el burnoutes un estrés crónico experimentado en el contexto laboral (Álvarez y Fernández, 1991).

FIGURA 3

\section{Productividad y desgaste}

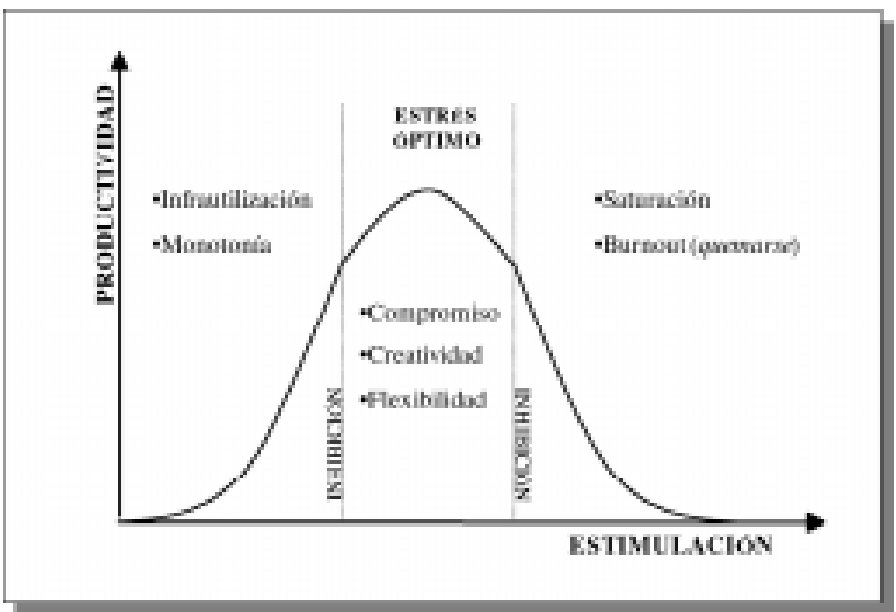

Fuente: elaboración propia a partir de García y Dolan (1997).

Todo el proceso que rodea al burnout es idiosincrásico, diferente de unos individuos a otros. Pese a esta dificultad, algunos síntomas comunes pueden agruparse en tres áreas: psico-emocionales, físicas y conductuales. Frecuentemente se centran en sentimientos de irritación, frustración, desesperanza y baja autoestima, dolencias diversas y sin causa conocida (jaquecas, reuma, insomnio...) y conductas de cinismo, dureza y falta de dedicación al trabajo. El agotamiento físico, mental y emocional, la sensación de vacío, de no tener nada que aportar a los demás, son los rasgos más característicos y universales (Pines y Aronson, 1988). Los tres componentes propuestos en el modelo de Maslach (despersonalización, agotamiento y ausencia de realización personal) constituyen síntomas prioritarios y dominantes. El contenido de cada uno de ellos sería el siguiente ${ }^{11}$ :

11 Una investigación sobre este asunto realizada con una muestra de directivos españoles puso de manifiesto que los principales factores desencadenantes del burnout eran el estilo de 
1) La despersonalización. Se trata de un estado psicológico de abandono del trabajo en el que se reacciona mostrando actitudes de deshumanización, inflexibilidad y cinismo. El trabajo se convierte en mera vigilancia, tratando a clientes y compañeros como personas-objeto, desprovistas de individualidad propia, derechos y emociones.

2) El agotamiento emocional. Puede ser físico (baja energía, cansancio crónico, debilidad general...), emocional (sentimientos de desamparo, desesperanza...) y mental (desarrollo de actitudes negativas hacia uno mismo, el trabajo y la vida en general). Las personas que esperan demasiado de sí mismas y de la organización en la que trabajan desarrollan más estrés interno, lo que conduce al agotamiento emocional. Al tener demasiado trabajo que realizar, el conflicto de roles y el tipo de interacciones interpersonales que se desarrollan en el trabajo se vuelven más conflictivos.

3) Ausencia de logro personal. Como resultado final el sujeto no se siente realizado en su trabajo, mostrando una dolorosa desilusión y frustración al no poder dar sentido a su profesión. Se experimentan sentimientos de fracaso personal (falta de competencia, de esfuerzo o conocimientos), de ausencia de expectativas y horizontes laborales y una insatisfacción generalizada. Este proceso concluye en desmotivación, actitudes autoritarias, pesimismo y desinterés por los colaboradores, en general, menor esfuerzo y dedicación al trabajo (impuntualidad, abundancia de interrupciones, evitación de tareas, absentismo...) y abandono de la profesión (Schawab, Jackson y Schuler, 1984).

Conviene tener en cuenta que de la misma forma que el estrés es una percepción individual - lo que para una persona supone un desafío excitante para otra puede representar un problema abrumador- en el desgaste profesional también se manifiesta este carácter relativo. En consecuencia, la determinación de si un trabajador está o no desgastado profesionalmente no es fácil de diagnosticar. El burnout no se presta a dicotomizaciones: no es un suceso, sino un proceso diferente en cada individuo (Farber, 1983) ${ }^{12}$.

dirección percibido, el conflicto de rol y el desajuste entre formación y responsabilidad del puesto de trabajo (Ariza y Morales, 1998).

12 En un intento de sistematizar los rasgos del burnouten la enseñanza, Farber (1991) ha sugerido la existencia de tres prototipos principales. Los profesores agotados son aquellos que reaccionan ante las excesivas demandas y los reveses en la enseñanza, trabajando cada vez menos y con más lentitud, puesto que no esperan alcanzar ningún objetivo. El segundo tipo son los profesores frenéticos, muy comprometidos con su trabajo y que reaccionan ante la 
Por tanto, la naturaleza altamente idiosincrática del burnout dificulta la integración de todos sus componentes constituyentes (causas, síntomas y sus relaciones). A pesar de ello se han propuesto diversos modelos que intentan describir las relaciones entre las distintas variables. Según Edel wich y Brodsky (1980) el proceso de desarrollo del burnout es cíclico, a través de la repetición de varios estadios sucesivos (entusiasmo, estancamiento, frustración y apatía) que conducen a la desilusión generalizada. En primer lugar entusiasmo, periodo inicial caracterizado por la existencia de altas expectativas y elevado nivel de energía. El trabajo promete serlo todo, el empleo llega a ser la única fuente de valores y satisfacciones, y las necesidades personales del trabajador (sentirse necesario, estimado, admirado, etc.) son circunscritas únicamente al entorno laboral. La siguiente etapa es de estanca miento. El trabajo ya no parece tan importante y se hace énfasis en la satisfacción de necesidades fuera del marco laboral. A continuación viene la frustración, periodo donde el profesional se cuestiona su propia valía y la del trabajo en sí. Ahora los límites del trabajo parecen amenazar los propósitos de lo que se está haciendo. Por último aparece la a pa tía, etapa en la que se piensa que el trabajo es sólo un trabajo. Las conductas que se derivan son: insuficiente dedicación, mínimo esfuerzo, evitación de los clientes o usuarios, etc. Se permanece en el trabajo únicamente por la seguridad que conlleva.

Los problemas originados por el estrés y el desgaste profesional son cada vez mayores ${ }^{13}$, hasta el punto de multiplicarse el número de empresas sancionadas judicialmente a indemnizar a empleados por inducirlos al trabajo excesivo. En España el problema aún no es grave, pero ya han aparecido algunos signos que insinúan la necesidad de actuar proactivamente en este sentido. Por ejemplo, de manera definitoria una reciente sentencia del Tribunal Supremo considera por primera vez el síndrome de estar quemado en el trabajo como accidente laboral. Este veredicto abre las

adversidad y los fracasos sin reconocerlos, incrementando más y más sus esfuerzos, en lugar de racionalizar y atemperar sus objetivos. Por último, los profesores infraincentivados serían aquellos que no encuentran en su trabajo suficientes estímulos, aunque ni se sienten agotados, ni estresados, ni tampoco perjudicados en su autoestima. Otros autores que han investigado el burnout en la enseñanza son CHerniss, 1980; FARBER, 1983 y MASLACH, 1982.

13 LaAsociación Americana de Psicología afirma que el 43,0\% de los adultos sufren estrés. Y sólo en Gran Bretaña, por citar un ejemplo, el estrés profesional supone un gasto de entre un $5 \%$ y un $10 \%$ del Producto Interior Bruto (citado por P. MATEY, El Mundo, Jueves 29 de enero de 1998. Suplemento Salud y Medicina). 
puertas para que numerosas bajas laborales y procesos de incapacidad permanente provocados por agotamiento psíquico de determinadas profesiones sean reconocidos como accidentes de trabajo. Una vez abierta la caja de Pandora detener sus consecuencias resulta misión imposible. Las empresas visionarias, aquellas que se adelantan al futuro y obtienen provecho de esta capacidad organizativa, ya están adoptando políticas internas y estrategias de futuro.

Las consecuencias más dramáticas de este afán desmedido por trabajar sin descanso ya han aparecido en otros países. Desde hace más de diez años se acuñó en J apón el siniestro término karoshi para referirse a la muerte por agotamiento debido al exceso de trabajo. El karoshi, que afecta sobre to do a hombres con edades comprendidas entre los 35 y los 50 años, es el estrés llevado hasta sus últimas consecuencias. Esta aberración de las sociedades occidentales consiste en un fallecimiento o incapacidad laboral de origen cardiovascular, que se produce cuando el empleado se ve sometido a una fuerte sobrecarga de trabajo. Un único dato nos proporciona una idea sobre sus devastadores efectos: algunos estudios apuntan a que la esclavitud laboral provoca que al menos diez mil japoneses fallezcan cada año.

El problema es de tal magnitud que las autoridades niponas están estudiando la posibilidad de dar cobertura aseguradora a un conjunto de acciones preventivas del karoshi. En otros países como Italia, ya existen sentencias firmes del Tribunal Supremo que establecen la obligatoriedad de resarcir económicamente a los empleados que sufran infartos $u$ otras lesiones psicofísicas como consecuencia de las muchas horas extras realizadas. El texto de la resolución entiende que el empleador no puede dejar de adoptar todas las medidas necesarias para tutelar la integridad psicofísica de los empleados, incluida la ampliación de la plantilla necesaria.

Quitando dramatismo al problema no se debe olvidar que la gran perjudicada de la dedicación compulsiva al trabajo es la salud del propio individuo y su entorno familiar.

\section{El equilibrio como desafio de futuro}

Pese a la preocupación aparente que existe sobre el asunto tratado en este trabajo, hemos concluido que se trata de una impresión más teórica que real. Algunos síntomas son evidentes: aumento de la adicción al trabajo, estrés, desgaste profesional y, en último término, karoshi. Para progresar en la 
búsqueda de la armonía vida personal-vida profesional, son necesarios dos instrumentos: mayor flexibilidad y un nuevo estilo de dirección.

En primer lugar, con relación a la flexibilidad laboral debemos apuntar que, aunque los mecanismos se han diversificado en los últimos años, su implantación en España aún está muy lejos de otros países de su entorno. Así lo demuestra la comparación de los resultados del estudio Work \& Life Balance (2001) en Finlandia, Reino Unido, Suiza y España. Casi un $60,0 \%$ de empresas españolas rechazan el trabajo a tiempo parcial, dato que contrasta con el $90,0 \%$ de empresas de Finlandia y el Reino Unido que sí ofrecen esta posibilidad a sus empleados. La flexibilidad en el horario es rechazada por un $40,0 \%$ de empresas españolas, mientras que en Finlandia más del 90,0\% permiten al trabajador adaptar el horario en función de sus intereses. Por otra parte, en España casi la mitad de empresas no ofrecen la posibilidad de escoger el período de vacaciones. Más del $80,0 \%$ de las empresas de Suiza y el Reino Unido ponen a disposición de sus empleados esta medida de flexibilidad. Finalmente, el $70,0 \%$ de las empresas españolas rechazan el teletrabajo que, sin embargo, es aceptado por un $70,0 \%$ de empresas del Reino Unido y Finlandia.

En segundo lugar, el estilo de dirección debe adaptarse al nuevo escenario. El desequilibrio vida personal-vida profesional se produce en un contexto, referido al mercado de trabajo, que cambia aceleradamente. Si en el pasado reciente la oferta de mano de obra superaba con creces a la demanda, las previsiones para el futuro inmediato muestran un cambio de tendencia radical. Así, las proyecciones del estudio Demografía, Mercado Laboral y Gestión de Personas, elaborado por la consultora Watson Wyatt, determinan una fecha de inflexión para esta tendencia ${ }^{14}$. Entre los años 2008 y 2009, el mercado laboral demandará más trabajadores de los disponibles. Este pleno empleo teórico plantea retos importantes a las empresas en política de atracción y retención de trabajadores cualificados.

Este nuevo marco de referencia exige un estilo de dirección innovador que sea capaz de recoger los cambios tanto en la mentalidad como en las estrategias a implementar. Las conclusiones del estudio Work \& Life Balance (2001) parecen mostrar un atisbo de esperanza, cuando menos entre los responsables de gestionar la política de recursos humanos. Una primera impresión a grandes rasgos evidencia un cambio de paradigma. Si en el

14 Iríbar, A., “Un futuro de pleno empleo”. El País, Negocios, domingo 9 de septiembre de 2001. 
pasado la búsqueda del orden entre vida personal y profesional se consideraba un beneficio social que la empresa concedía al trabajador, en la actualidad los directores de recursos humanos están asumiendo que fo mentar este equilibrio produce efectos beneficiosos para ambas partes.

De esta manera, más del $90,0 \%$ de los responsables de recursos humanos participantes en el estudio opinan que los mejores trabajadores son los que logran un equilibrio óptimo entre tra bajo y vida personal. Por consiguiente... ilas empresas deben ayudar a encontrar el punto de equilibrio! (nueve de cada diez directivos sostienen este punto de vista). La flexibilidad constituye un instrumento básico para conseguir este objetivo. Además, según el 95,0\% de los directivos del área de recursos humanos, la flexibilidad laboral... ¡no reduce la eficiencia!

En definitiva, la búsqueda del equilibrio vida personal-profesional parece el camino más directo para prevenir desenlaces perniciosos. Una cultura que propicie la relación y no sólo la eficiencia, y una visión estratégica de los recursos humanos, constituyen factores determinantes para equilibrar esta situación que, aunque parece producir resultados positivos a corto plazo, tiene efectos desastrosos para la organización y para el individuo a medio y largo plazo. Unos trabajadores equilibrados ofrecen mejores ideas, son más participativos y, en consecuencia, ambas partes obtienen beneficios.

\section{Bibliografía}

Álvarez, E. y Fernández, L. (1991), "El Síndrome de «burnout»o el desgaste profesional: Revisión de estudios", Revista de la Asociación Española de Neuropsiquiatría, no 21, pp. 257-65.

Ariza, J .A. (2001), “El credo de la conciliación”, Andalucía Económica, no 118, enero, pp. 84.

Ariza, J .A. y Morales, A.C. (1998), "Desgaste y despersonalización del directivo: un estudio empírico", Estudios empresariales, no 98, pp. 48-58, 3.

Burin, M. (2000), “Cuando el trabajo es adicción”, Clarín digital. Lunes 13 de marzo.

Centro de Investigaciones Sociológicas, CIS (1997), "Trabajar un problema, una razón". Boletín no 11, junio; http://www.cis.es/boletin/11/est4.html. 
- (2000), “El año 2000”. Boletín no24, abril-junio; http://www.cis.es/boletin/ 24/2000.htm.

Cherniss, C. (1980), Professional Burnout in Human service organizations, Nueva York, Prager.

Creade (2001), Work and Life Balance; www.work-and-life-balance.com.

EdelWich, J. y Brodsky, A. (1980), "Burnout: Stages of Disilusionment in the Helping Professional", Human Sciences Press, New York.

Farber, B.A. (1983), "Stress and Burnout in the Human Service Professions. Pergamon", General Psychology Press, New York.

Farber, B.A. (1991), Crisis in Education. Stress and Burmout in the American Teacher, San Francisco, J ossey-Bass Publishers.

Freudenberger, H.J . (1974), "Staff Burn-out”, J ournal of Social Issues, no 30, pp. $159-65$.

García, S. y Dolan, S. L. (1997), La dirección por valores, Madrid, McGraw-Hill.

González de Rivera, J. L. (1978), “Metabolismo y funciones generales de las catecolaminas. Estudio de su acción en la secreción neuroendocrina y el comportamiento", Anales de la Real Academia de Medicina, no95, pp. 67781.

HeRnÁndez, C. (1999), "Disparidad de jornada y reducción del tiempo de trabajo", Capital Humano, no 128, Diciembre.

Instituto VAsco de Estadística. Eustat (1998), Demografía y hábitos sociales. Uso social del tiempo; http://www.eustat.es/varios/informes/inf865.pdf.

MASLACH, C. (1982), Burnout: The cost of caring, Englewood Clifts, N.J ., Prentice Hall.

Pines, A. y Aronson, E. (1988), Carer Burnout Causes and Cures, New York, The Free Press.

SchaWAB, R. L., J ACKSON, S. E. y ShuleR, R. S. (1986), “Educator burnout: sources and consequences", Educational Research Quaterly, no 10, pp. 14-30. 